\title{
Association of oxamniquine praziquantel and clonazepam in experimental Schistosomiasis mansoni
}

\author{
Neusa Araujo/ ${ }^{+}$, Ana Carolina Alves de Mattos, Paulo Marcos Zech Coelho/ ${ }^{1}$, Naftale Katz ${ }^{1}$ \\ Laboratório de Esquistossomose, Instituto René Rachou-Fiocruz, Av. Augusto de Lima 1715, 30190-002 Belo Horizonte, MG, Brasil \\ ${ }^{1}$ Santa Casa de Belo Horizonte, Belo Horizonte, MG, Brasil
}

The antischistosomal activity of clonazepam, when administered alone or in association with oxamniquine and praziquantel, was experimentally evaluated in mice infected with Schistosoma mansoni. The animals were treated 45 days post-infection with a single dose, by oral route, according to three treatment schedules: clonazepam $25 \mathrm{mg} /$ $\mathrm{kg}$ and sacrificed $15 \mathrm{~min}, 1 \mathrm{~h}$ or $4 \mathrm{~h}$ after treatment; clonazepam 1.0, $2.5 \mathrm{or} 10.0 \mathrm{mg} / \mathrm{kg}$ and sacrificed 15 days posttreatment or with the dose of $10 \mathrm{mg} / \mathrm{kg}$ in association with oxamniquine $50 \mathrm{mg} / \mathrm{kg}$ or praziquantel $200 \mathrm{mg} / \mathrm{kg}$, single dose, orally, every schedule with a control group. The efficacy of the drugs in vivo was assessed by means of worm counts and their distribution in mesentery and liver, mortality and oogram changes. In the chemotherapeutic schedules used, clonazepam did not present antischistosomal activity and the result of the association of this drug with oxamniquine or praziquantel was not significantly different from the one obtained when these two last drugs were administered alone. In the in vitro experiments, the worms exposed to $0.6 \mathrm{mg} / \mathrm{mL}$ clonazepam remained motionless throughout the 8-day-period of observation, without egg-laying, whereas the worms of the control group showed normal movements, egg-laying and hatching of miracidia on the last day of observation. The results obtained in the present study confirm the action of clonazepam on $\mathrm{S}$. mansoni adult worm, in vitro, causing total paralysis of males and females. However, no additive or synergistic effects were observed when clonazepam were used in association with oxamniquine or praziquantel.

Key words: Schistosoma mansoni - clonazepam - drug association

The most efficient measure for the morbidity control of schistosomiais is the treatment of infected patients. According to Savioli et al. (2004), the antischistosomal drugs play an important role for the treatment of infection and for the control of morbidity and transmission.

In spite of oxamniquine and praziquantel, that are the two available antischistosomal drugs for treatment of the disease, being efficient and presenting few side effects, some relevant aspects must be considered. Oxamniquine has a complicated manufacturing process, requiring big fermentation tanks for biological synthesis, resulting in a high cost, when compared to praziquantel. Due to this difficulty, praziquantel has been practically the unique drug utilized at the moment, and the use of a single drug in a mass scale and in recurrent treatments may result in the emergence of resistant strains.

For the reasons above, it is clear that there is the need for new and effective drugs, or new alternatives for the treatment of schistosomiasis. In our laboratories, a large project to find new antischistosomal drugs is being conducted. One attempt is to use known antischistosomal agents (mainly oxamniquine or praziquantel) in association with other drugs that may increase the activity of these known schistosomicides. In this context, we re-

Financial support: FIOCRUZ, FAPEMIG

+Corresponding author: araujon@cpqrr.fiocruz.br

Received 18 June 2008

Accepted 6 November 2008 cently demonstrated that the concomitant use of lovastatine (potent inhibitor of the synthesis of cholesterol) produces in vitro and in vivo action against egg production and development (Araujo et al. 2008). Clonazepam belongs to the chemical group known as benzodiazepines, the main properties of which are mild inhibition of the functions of the central nervous system with anticonvulsive and sedative activity, muscular relaxant and tranquilizer effects, as its main proprieties. Clonazepam as an antischistosomal agent was quoted for the first time at Hoffman-La Roche Laboratories by Stohler (1978). Pax et al. (1978) revealed that Schistosoma mansoni worms incubated in clonazepam concentrations presented muscular contractions and remained motionless, thus resulting in the antischistosomal effect of the drug. Studies performed by Bennett (1980) suggested that the male worms of $S$. mansoni present binding sites for benzodiazepines in their tegument.

Based on these studies, this work investigates the antischistosomal activity of clonazepam in experimentally infected mice with $S$. mansoni, as well as its association with oxamniquine and praziquantel, well known antischistosomal medicines. In vitro studies were also carried out to observe the possible damages caused in $S$. mansoni worms by clonazepam.

\section{MATERIAL AND METHODS}

Experimental chemotherapy - Swiss mice (mean weight $20 \mathrm{~g}$ ) were infected by subcutaneous route with $100 \pm 10$ cercariae of S. mansoni (LE strain). The Guidelines of the Ethical Committee for the use of experimental animals of the Fiocruz were followed. Forty-five days 
post-infection, groups of animals were orally treated, single dose, according to three schedules: $25 \mathrm{mg} / \mathrm{kg}$ clonazepam (Medley Industry) and sacrificed $15 \mathrm{~min}, 1 \mathrm{~h}$ or $4 \mathrm{~h}$ after treatment; $1.0,2.5,5.0$ or $10.0 \mathrm{mg} / \mathrm{kg}$ clonazepam and sacrificed 15 days after treatment; $10 \mathrm{mg} / \mathrm{kg}$ clonazepam associated to $50 \mathrm{mg} / \mathrm{kg}$ oxamniquine (Man$\mathrm{sil}^{\circledR} /$ Pfizer), or to $200 \mathrm{mg} / \mathrm{kg}$ praziquantel (Farmanguinhos/Fiocruz), simultaneously with the control groups. The animals were sacrificed by cervical fracture and perfusion was performed for collecting worms in the mesentery and liver. The same procedures were adopted for the control groups constituted by infected and untreated mice (Pellegrino \& Katz 1968).

In vivo activity evaluation - Drug activity was assessed by means of perfusion of the animals pertaining to treated and control groups, considering the mean of the number of worms, rates of worm distribution in the mesentery and liver, dead worms in the liver and oogram changes (Pellegrino et al. 1962).

In vitro trials - Mice infected with $S$. mansoni cercariae (LE strain) were sacrificed using sodium pentobarbital $3 \%$ (30 $\mu \mathrm{L} /$ mice) and perfused according to the technique by Smithers and Terry (1965). The collected worms were distributed into plates of six wells each (4 pairs of worms per well and kept in culture medium RPMI-1640 supplemented with 5\% fetal bovine serum, $100 \mu \mathrm{g} / \mathrm{mL}$ of antibiotics penicillin/streptomycin). In the experimental group, the worms were exposed to clonazepam at the dose of $0.6 \mathrm{mg} / \mathrm{mL}(1 \mathrm{~mL}$ of pediatric clonazepam, $2.5 \mathrm{mg} / \mathrm{mL}$ in $3 \mathrm{~mL}$ of culture medium) for $24 \mathrm{~h}$ and maintained in incubator at $37^{\circ} \mathrm{C}$ and $5 \% \mathrm{CO}_{2}$. In the control group, the worms were kept under the same conditions, except for the presence of the drug. Afterwards, the worms were washed with culture medium and maintained under the same previous conditions, but without drug addition throughout the rest of the trial. Observations under inverted microscope were documented $1 \mathrm{~h}$ after drug contact 5, 24, 48, 72 and $96 \mathrm{~h}$ after drug discontinuation and eight days after the beginning of the experiment. The culture medium was changed in alternate days. The experiments were performed in duplicate and repeated twice ( 2 experiments).

Statistical analysis - The results obtained were compared by means of the Student's $t$ test, $\mathrm{p} \geq 0.05$ being stipulated as significance level.

\section{RESULTS}

The results obtained with experimentally infected mice with $S$. mansoni (LE strain), treated with clonazepam $25 \mathrm{mg} / \mathrm{kg} /$ body weight, single dose, by oral route, and sacrificed $15 \mathrm{~min}, 1 \mathrm{~h}$ or $4 \mathrm{~h}$ after treatment can be seen in Table I. In the treated animals, a discrete migration of the worms ( $\mathrm{ca} 30 \%)$ to the liver could be observed, whereas in the animals of the control group this displacement was about 10\% (not significant difference). No dead worms in the liver, as well as oogram changes were observed.

Table II shows the results obtained in mice treated with clonazepam $1.0,2.5,5.0$ or $10.0 \mathrm{mg} / \mathrm{kg}$ and sacrificed $4 \mathrm{~h}$ or 15 days after treatment. No significant differences were presented by the animals of the treated groups when compared with the control group. It is worth highlighting that the animals treated with the highest dose $(25 \mathrm{mg} / \mathrm{kg}$ body weight) remained sedated for at least $3 \mathrm{~h}$, being recovered after this period. In none of the groups could be found a dead animal due to sedation.

The results of the trial with $10 \mathrm{mg} / \mathrm{kg}$ clonazepam in association with $50 \mathrm{mg} / \mathrm{kg}$ oxamniquine or with $200 \mathrm{mg} /$ $\mathrm{kg}$ praziquantel are indicated in Table III. In the animals treated with clonazepam alone, a worm mortality rate of $6.8 \%$ could be observed, however, the other parameters did not show any change when compared with the control group. The results obtained in animals treated with clonazepam alone did not present significant differences, when compared with those obtained in animals treated with clonazepam in association with oxamniquine or praziquantel.

In vitro trials - The worms exposed to clonazepam could be seen motionless $1 \mathrm{~h}$ after contact with the drug, and so they remained throughout the rest of the experiment (Table IV). In the first trial, some worms could be seen contracted, when the observation was performed $48 \mathrm{~h}$ after the beginning of the experiment. In the second trial, the worms remained motionless and some blisters appeared in the tegument up to the 8th day of observation. S. mansoni eggs could not be seen in the experimental wells. The worms in the control groups appeared with normal movements and morphology, presenting eggs during the first $24 \mathrm{~h}$, with the presence of newly hatched miracidia, when examined eight days after the beginning of the experiment (Figure).

\section{TABLE I}

Results obtained in mice experimentally infected with $100 \pm 10$ cercariae of Schistosoma mansoni (LE strain) treated with clonazepam $25 \mathrm{mg} / \mathrm{kg}$ body weight, single dose, orally, 45 days after infection

\begin{tabular}{|c|c|c|c|c|c|c|}
\hline \multirow{2}{*}{$\begin{array}{l}\text { Time } \\
\text { after treatment }\end{array}$} & \multirow{2}{*}{$\begin{array}{c}\text { Number of } \\
\text { animals examined }\end{array}$} & \multirow{2}{*}{$\begin{array}{l}\text { Mean of } \\
\text { worms }\end{array}$} & \multicolumn{2}{|c|}{$\begin{array}{c}\text { Distribution of worms } \\
\%\end{array}$} & \multirow{2}{*}{$\begin{array}{c}\text { Dead worms } \\
\text { in the liver } \\
\%\end{array}$} & \multirow{2}{*}{$\begin{array}{c}\text { Oogram } \\
\text { changes } \\
\%\end{array}$} \\
\hline & & & Mesentery & Liver & & \\
\hline $15 \mathrm{~min}$ & 3 & 13.3 & 80.0 & 20.0 & 0.0 & 0.0 \\
\hline $1 \mathrm{~h}$ & 3 & 7.5 & 73.3 & 26.7 & 0.0 & 0.0 \\
\hline $4 \mathrm{~h}$ & 3 & 14.0 & 69.0 & 31.0 & 0.0 & 0.0 \\
\hline Control & 3 & 10.6 & 90.6 & 9.4 & 0.0 & 0.0 \\
\hline
\end{tabular}


TABLE II

Results obtained in mice experimentally infected with $100 \pm 10$ cercariae of Schistosoma mansoni (LE strain), treated with clonazepam, single dose, orally, 45 days after infection

\begin{tabular}{|c|c|c|c|c|c|c|c|c|}
\hline \multirow{2}{*}{$\begin{array}{l}\text { Treatment } \\
\text { schedule } \\
\mathrm{mg} / \mathrm{kg}\end{array}$} & \multirow{2}{*}{$\begin{array}{c}\text { Time } \\
\text { after treatment }\end{array}$} & \multicolumn{2}{|c|}{ Number of animals ${ }^{a}$} & \multirow{2}{*}{$\begin{array}{l}\text { Mean of } \\
\text { worms }\end{array}$} & \multicolumn{2}{|c|}{$\begin{array}{c}\text { Distribution } \\
\text { of worms } \\
\% \\
\end{array}$} & \multirow{2}{*}{$\begin{array}{c}\text { Dead worms } \\
\text { in the liver } \\
\%\end{array}$} & \multirow{2}{*}{$\begin{array}{c}\text { Oogram } \\
\text { changes } \\
\%\end{array}$} \\
\hline & & Treated & Examined & & Mesentery & Liver & & \\
\hline 1.0 & $4 \mathrm{~h}$ & 3 & 3 & 6.7 & 85.0 & 15.0 & 0.0 & 0.0 \\
\hline 1.0 & 15 days & 5 & 5 & 14.0 & 97.1 & 2.9 & 0.0 & 0.0 \\
\hline 2.5 & $4 \mathrm{~h}$ & 3 & 3 & 9.3 & 85.7 & 14.3 & 0.0 & 0.0 \\
\hline 2.5 & 15 days & 5 & 5 & 14.8 & 86.5 & 13.5 & 0.0 & 0.0 \\
\hline 5.0 & $4 \mathrm{~h}$ & 3 & 3 & 11.0 & 90.9 & 9.1 & 0.0 & 0.0 \\
\hline 5.0 & 15 days & 5 & 3 & 8.3 & 84.0 & 16.0 & 0.0 & 0.0 \\
\hline 10.0 & $4 \mathrm{~h}$ & 3 & 3 & 8.0 & 95.8 & 4.2 & 0.0 & 0.0 \\
\hline 10.0 & 15 days & 5 & 1 & 7.0 & 100.0 & 0.0 & 0.0 & 0.0 \\
\hline Control & - & - & 5 & 15.6 & 88.5 & 11.5 & 0.0 & 0.0 \\
\hline
\end{tabular}

$a$ : the difference between the number of treated animals and examined animals means the number of dead animals.

\section{TABLE III}

Results obtained in experimentally infected mice with $100 \pm 10$ Schistosoma mansoni cercariae treated 45 days after infection with $10 \mathrm{mg} / \mathrm{kg}$ clonazepam (CLO) alone or in association with $50 \mathrm{mg} / \mathrm{kg}$ oxamniquine (OXA) or $200 \mathrm{mg} / \mathrm{kg}$ praziquantel (PZQ), single dose, orally, and sacrificed 15 days post-treatment. There was no significant difference between the results obtained with oxamniquine and praziquantel when administered alone and those ones obtained with these two drugs in association with clonazepam.

\begin{tabular}{|c|c|c|c|c|c|c|c|c|}
\hline \multirow[b]{2}{*}{ Drug } & \multirow{2}{*}{$\begin{array}{l}\text { Treatment } \\
\text { schedule } \\
\mathrm{mg} / \mathrm{kg}\end{array}$} & \multicolumn{2}{|c|}{ Number of animals } & \multirow{2}{*}{$\begin{array}{c}\text { Mean } \\
\text { of worms }\end{array}$} & \multicolumn{2}{|c|}{$\begin{array}{c}\text { Worm } \\
\text { distribution \% }\end{array}$} & \multirow{2}{*}{$\begin{array}{l}\text { Dead worms } \\
\text { in the liver \% }\end{array}$} & \multirow{2}{*}{$\begin{array}{c}\text { Oogram } \\
\text { changes \% }\end{array}$} \\
\hline & & Treated & Examined & & Mesentery & Liver & & \\
\hline OXA & 50 & 14 & 14 & 6.2 & 62.1 & 37.9 & 32.2 & 50.0 \\
\hline PZQ & 200 & 14 & 14 & 9.7 & 36.8 & 63.2 & 56.6 & 42.9 \\
\hline CLO & 10 & 14 & 14 & 10.2 & 79.5 & 20.5 & 6.8 & 0.0 \\
\hline $\mathrm{CLO}+\mathrm{OXA}$ & $10+50$ & 14 & 14 & 9.3 & 40.0 & 60.0 & 56.2 & 64.3 \\
\hline CLO + PZQ & $10+200$ & 14 & 14 & 13.6 & 32.6 & 67.4 & 61.0 & 42.9 \\
\hline Control & - & - & 14 & 12.6 & 86.4 & 13.6 & 0.0 & 0.0 \\
\hline
\end{tabular}

TABLE IV

Results obtained in in vitro experiments using adult Schistosoma mansoni worms exposed to clonazepam at the dose of $0.6 \mathrm{mg} / \mathrm{mL}$

\begin{tabular}{|c|c|c|}
\hline Group & Period of observation & Observations (worms) \\
\hline Experimental & $1 \mathrm{~h}$ of contact & motionless, paired, without contraction, normal morphology, absence of eggs \\
\hline $\begin{array}{l}\text { Control } \\
\text { Experimental }\end{array}$ & $24 \mathrm{~h}$ of contact & $\begin{array}{l}\text { live, paired, normal movements and mo } \\
\text { motionless paired absence of eggs }\end{array}$ \\
\hline Control & & $\begin{array}{l}\text { live, paired, normal movements and morphology, } \pm 100 \text { eggs at the first stage } \\
\text { and dead }\end{array}$ \\
\hline Experimental & $5 \mathrm{~h}$ after contact & motionless, paired, absence of eggs \\
\hline Control & & $\begin{array}{l}\text { live, paired, normal movements and morphology, } \pm 100 \text { eggs alt the first stage } \\
\text { and dead }\end{array}$ \\
\hline Experimental & $24 \mathrm{~h}$ after contact & $\begin{array}{l}\text { motionless, } 2 \text { pairs of mated worms and } 3 \text { unmated other ones, contracted, } \\
\text { absence of eggs }\end{array}$ \\
\hline Control & & $\begin{array}{l}\text { live, paired, normal movements and morphology, } \pm 150 \text { eggs at } 1 \text { st and } 2 \text { nd } \\
\text { stages and dead }\end{array}$ \\
\hline Experimental & $48 \mathrm{~h}$ after contact & motionless, absence of eggs \\
\hline Control & & $\begin{array}{l}\text { live, paired, normal movements and morphology, eggs at the 1st, 2nd, 3rd and } \\
\text { 4th stages and dead }\end{array}$ \\
\hline $\begin{array}{l}\text { Experimental } \\
\text { Control }\end{array}$ & 7 days after contact & $\begin{array}{l}\text { motionless, apparently without damages in the tegument, absence of eggs } \\
\text { live, paired, normal movements and morphology, eggs at all developmental } \\
\text { stages, presence of hatched miracidia but dead }\end{array}$ \\
\hline
\end{tabular}




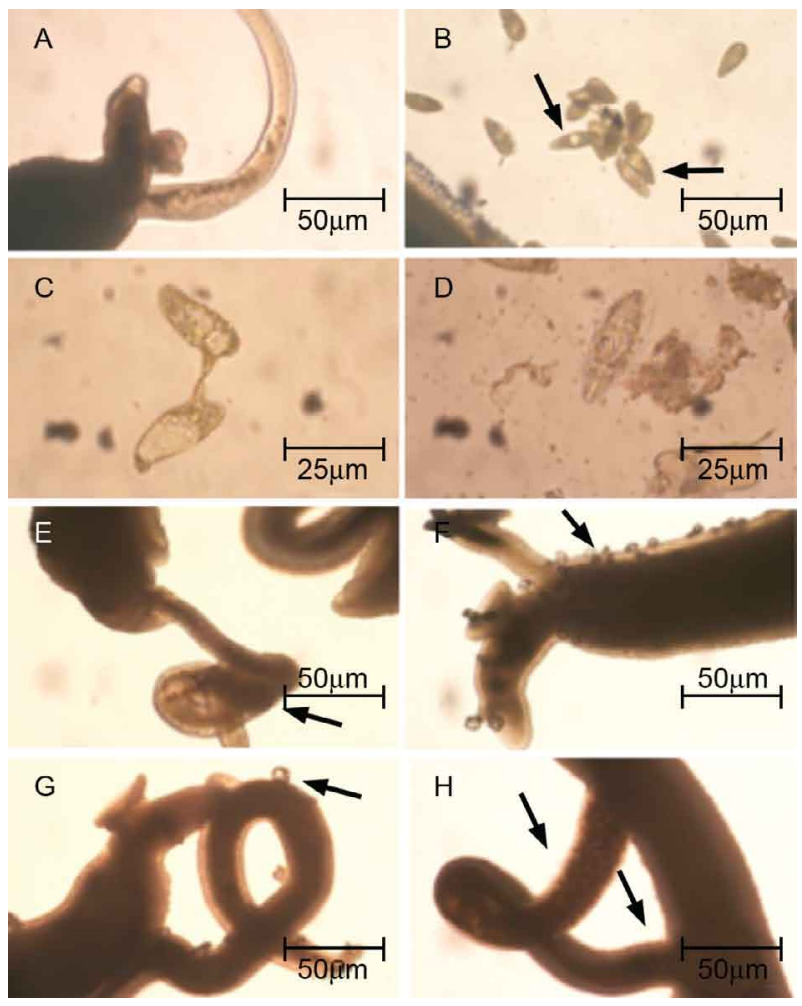

Evaluation of the in vitro activity of clonazepam on Schistosoma mansoni worms. Control group not exposed to the drug. A: paired adult worms without apparent morphological change, two days of culture; B: presence of eggs of 1st (arrow) and 2nd (head of the arrow) stages, two days of culture; C: presence of eggs at the 4th stage, eight days of culture; D: presence of hatched miracidium, eight days of culture. Evaluation of the in vitro activity of clonazepam on S. mansoni worms. Group exposed to $0.6 \mathrm{mg} / \mathrm{mL}$ of the drug; E: adult worms: paired, motionless and contracted (female/arrow), two days of culture; F, G: adult worms: paired, motionless and contracted ( 2 and 3 days of culture, respectively), presence of crystals adhered to the worm tegument (arrow); H: paired female and male presenting separation of the tegument (arrow), eight days of culture. In none of the observations eggs in the groups exposed to clonazepam could be detected.

\section{DISCUSSION}

The results obtained show that clonazepam did not present antischistosomal activity in vivo when administered alone, nor addictive or synergistic action, when used in association with antischistosomal drugs (oxamniquine and praziquantel).

Stohler (1978) identified the benzodiazepines clonazepam and RO 11-3128 (methylclonazepam) as being antischistosomal drugs. That author showed that RO 113128 was highly effective against $S$. mansoni infection, similar to niridazole, hycanthone and oxamniquine. In vitro, when added at a concentration of $6.25 \mu \mathrm{g} / \mathrm{mL}$ to the medium containing $S$. mansoni male worms, contraction of these worms could be observed after some seconds. In hamsters, the activity against Schistosoma haematobium was similar to that showed for S. mansoni.
However, infection due to Schistosoma japonicum was resistant to treatment when using hamsters treated with doses up to $150 \mathrm{mg} / \mathrm{kg}$ administered in five times. Pax et al. (1978) studied the activity of benzodiazepine RO 113128 and of praziquantel in the musculature of $S$. mansoni and $S$. japonicum worms and showed that at low concentrations this compound causes tension, paralysis and lack of movement in male worms. Bennett (1980), in vitro studies using $20 \mathrm{~S}$. mansoni male worms and 20 also of $S$. japonicum, incubated at $37^{\circ} \mathrm{C}$ for $10 \mathrm{~min}$ in $2.0 \mathrm{~mL}$ of Earl's solution and varying the concentration of benzodiazepine RO 11-3128, suggested that $S$. mansoni male worm is endowed with a specific binding site, when this worm presents an intact tegument. These binding sites were clearly changed in presence of agents that, as it is well known, are able to destroy the membrane integrity. Boyle et al. (1985) evaluated the effect of meclonazepam (3-methylclonazepam) in volunteers, using single doses of 1, 2 and $4 \mathrm{mg}$, orally, and reported that the doses higher than $1 \mathrm{mg}$ caused dose-dependent damages in the cognitive and psychomotor functions of patients, as well as mood changes and ataxia. These effects could be markedly observed at the first $3 \mathrm{~h}$ after drug administration and a mild sedation up to $6 \mathrm{~h}$ after drug administration of $4 \mathrm{mg}$. The authors suggest, as a result of the findings, that the use of benzodiazepines as antischistosomal drugs needs further investigation. Leite and Monteiro (2007) studied the participation of the binding sites in the contractive activity of clonazepam and 3-methylclonazepam on S. mansoni worms. Male adult worms were placed on glass slides containing saline solution and the muscular contraction effect of benzodiazepines was evaluated through the reduction of the body area, measured by analysis of the images captured by cameras. They observed that the utilized benzodiazepines at the concentration of $10 \mu \mathrm{M}$ led to worm contraction in a time-dependent manner, similar to that of praziquantel, when used at the concentration of $1 \mu \mathrm{M}$. Based on these results, they concluded that the effect of contraction caused by both benzodiazepines is not due either to a direct effect in the worm muscle or as a result of binding to one of the two benzodiazepinic receptors present in S. mansoni. Noel et al. (2007) investigated the presence of gama-aminobutyric acid (GABA) in $S$. mansoni adult worms, using [3H]-flunitrazepam to label the alosteric binding sites of the benzodiazepinic receptors and detected a large number of binding sites to $[3 \mathrm{H}]$-flunitrazepam in the great majority of the worm population. The authors describe the pharmacological proprieties of some diazepine receptors as possible targets for the development of new antischistosomal drugs. The presence of benzodiazepinic peripheral receptors in the parasite was found for the first time by Noel et al. (2007). Pica-Mattoccia et al. (2008) studied the mode of action of RO11-3128 (methyl-clonazepam) and praziquantel, in vitro and in vivo, on Schistosoma worms. Both drugs cause paralysis, influx of the calcium ducts and damages in the parasites' tegument. Since it is well known that RO 11-3128 is active against immature 
worms of $S$. mansoni and praziquantel is ineffective at this phase, praziquantel being active against $S$. japonicum, whereas RO 11-3128 is inactive, the excess of one drug on another one was studied. It was verified that the excess of praziquantel does not inhibit the activity of RO 11-3128 on $S$. mansoni immature worms and an excess of RO 11-3128 does not inhibit the efficacy of praziquantel on $S$. japonicum, suggesting that the binding site of the worm with both drugs is rather different. On the other hand, when cytochalasin D, an agent that blocks the calcium channel, was used it inhibited the activity of both agents. Association of these results suggests that both drugs, although binding themselves at different receptor sites in the parasite, present the same schistosomicidal mechanism (Picca-Mattoccia et al. 2008).

It must be highlighted that in the majority of the studies above mentioned, the activity of clonazepam and RO 11-3128 was observed in male worms of $S$. mansoni proceeding from unisexual infections. Pica-Mattocia et al. (2008) showed the activity of praziquantel and RO 113128 on S. japonicum adult worms, males and females, and reported that praziquantel was found to be more active against male worms. Pre-incubation with RO 11-3128 for $1 \mathrm{~h}$ before addition of praziquantel did not affect the activity of this last drug (Picca-Mattoccia et al. 2008).

The results obtained in the present study confirm the action of clonazepam on $S$. mansoni adult worm, in vitro, causing total paralysis of males and females. However, with the therapeutic schedules used in experimentally infected mice, it was not possible to detect any activity against $S$. mansoni, when clonazepam was administered alone or in association with oxamniquine or praziquantel. No addictive or synergistic effects were observed when clonazepam was used in association with these two known antischistosomal drugs.

\section{ACKNOWLEDGEMENT}

To Dr. John R. Kusel, for his suggestions and reviewing of manuscript.

\section{REFERENCES}

Araújo N, Mattos ACA, Sarvel AK, Coelho PMZ, Katz N 2008 Oxamniquine, praziquantel and lovastatin association in the experimental Schistosomiasis mansoni. Mem Inst Oswaldo Cruz 103: 450-454.

Bennett JL 1980. Characteristics of antischistosomal benzodiazepine binding sites in Schistosoma mansoni. J Parasitol 66: 742-747.

Boyle CO, Lambe R, Darraugh A 1985. Central effects in man of the novel schistosomicidal benzodiazepine meclonazepam. Eur $J$ Clin Pharmacol 29: 105-108.

Leite CC, Monteiro LM 2007. Efeitos contraturantes do clonazepam e 3-metilclonazepam em Schistosoma mansoni adultos e sua relação com sítios de ligação benzodiazepínicos. In XXIX Jornada Giulio Massarani de Iniciação Científica e Cultural da UFRJ, Vol. 1, UFRJ, Rio de Janeiro, resumo 2543, p. 435.

Noel F, Mendonça-Silva DL, Thibaut JP, Lopes DV 2007. Characterization of two classers of benzodiazepine binding sites in Schistosoma mansoni. Parasitology 22: 1-10.

Pax R, Bennett JL, Fetterer R 1978. A benzodiazepine derivative and praziquantel: effects on musculature of Schistosoma mansoni and Schistosoma japonicum. Naunyn Schmiedebergs Arch Pharmacol 304: 309-315.

Pellegrino J, Katz N 1968. Experimental chemotherapy of Schistosomiasis mansoni. Adv Parasitol 6: 233-290.

Pellegrino J, Oliveira CA, Faria J, Cunha AS 1962. New approach to screening of drugs in experimental Schistosomiasis mansoni in mice. Am J Trop Med Hyg 11: 201-215.

Picca-Mattoccia L, Ruppel A, Xia CM, Cioli D 2008. Praziquantel and the benzodiazepines RO 11-3128 do not compete for the same binding sites in schistosomes. Parasitology 135: 47-54.

Savioli L, Albonico M, Engels D, Montresor A 2004. Progress in the prevention and control of Schistosomiasis and soil-transmitted helminthiasis. Parasitol Int 53: 103-113.

Smithers SR, Terry RJ 1965. The infection of laboratory hosts with cercariae of Schistosoma mansoni and the recovery of adult worms. Parasitology 55: 695-700.

Stohler HR 1978. RO 11-3128 - a novel schistosomicidal compound. 'Proceedings of the 10th International Congress of Chemotherapy, Vol. 1, American Society for Microbiology, Washington DC, p. $147-148$ 